This item was submitted to Loughborough's Research Repository by the author.

Items in Figshare are protected by copyright, with all rights reserved, unless otherwise indicated.

\title{
Geographical gerontology: perspectives, concepts, approaches [Book Review]
}

PLEASE CITE THE PUBLISHED VERSION

PUBLISHER

Taylor \& Francis (Routledge)

\section{VERSION}

AM (Accepted Manuscript)

\section{PUBLISHER STATEMENT}

This is an Accepted Manuscript of an article published by Taylor \& Francis in Social and Cultural Geography on 16 February 2019, available online: http://www.tandfonline.com/10.1080/14649365.2019.1584152.

\section{LICENCE}

CC BY-NC-ND 4.0

\section{REPOSITORY RECORD}

Lulle, Aija. 2019. "Geographical Gerontology: Perspectives, Concepts, Approaches [book Review]”. figshare. https://hdl.handle.net/2134/37362. 
Geographical gerontology: Perspectives, concepts, approaches. Perspectives, Concepts, Approaches, 1st Edition, Edited by Mark W. Skinner, Gavin J. Andrews, Malcolm P. Cutchin. London and New York: Routledge, 2018. Hardback: $9781138241152, £ 93.50$

\title{
Geographical gerontology. Perspectives, concepts, approaches
}

\author{
Reviewed by Aija Lulle \\ Loughborough University \\ a.lulle@,lboro.ac.uk
}

'Geographical gerontology: Perspectives, concepts, approaches,' released in 2018, is a long awaited and excellent collection of contributions which exemplify a geographical take on ageing. This book deserves to have a long and healthy shelf life in universities and beyond. The collection, edited by three renowned scholars in the field, Mark W. Skinner, Gavin J. Andrews and Malcolm P. Cutchin. It comprises high-quality, well-chosen and edited contributions by 30 authors.

Most of the contributors are also well-known scholars, who have authored 24 chapters of this book. The chapters are divided in five parts. The first part, Introduction, comprises two contributions: an overview of geographical gerontology, and theoretical traditions in this distinct geographical field. Geographies of ageing, the authors emphasise, have flourished since the 1970 s, while the 'spatial turn' within social gerontology is more recent. Part II, Geographical perspectives on ageing, scrutinises studies in health geography, population geographies, planning and design, and environment and ageing. Part III, Geographical scales of inquiry, includes contributions on the global scale, ageing in low- and middle-income countries, urban and rural ageing, household spaces, and embodiment and emotions in later life, all written from a socio-spatial perspective. Contributions in this part also remind us that critical attention needs to be devoted to the 'translation' of approaches from global to local scales through interdisciplinary work.

Next part, IV, Key issues in geographical gerontology, has 10 chapters dealing with issues from place experiences to relationships, mobilities, care provisions and therapeutic landscapes. Finally, the firth section, Discussion, critically addresses the challenges of interdisciplinarity, assesses progress and sheds light on future research possibilities.

This collection, taken together, outlines and pushes forward a dual agenda in both geographies of ageing and gerontology. The specificity of the book is its clear geographical focus: where does ageing occur, in what ways is ageing transforming societies in certain places, and how is it experienced by people. Ageing is highly contingent: it is shaped by times, spaces and places. Such pertinent questions, with their spatio-temporal focus, also address implications for policies and institutions, which must grapple with ageing issues in this century.

The collection provides a comprehensive and meaningful overview of perspectives, concepts and approaches in a systematic and easy accessible way for a professional geographer. Throughout the book, contributions take into account and engage in analysis of the reflective, transactional and mutually constitutive relationships between people and the spaces and places in which ageing occurs.

The book also provides an overview for those who want to be better able to target policies, outlining how politics play out spatially and have spatial implications. Generations of theoretical insights and different schools of thought are not overlooked also in policy analysis. For instance, there is an approach from spatial and population science, with its central emphasis on volumes, demands, and distances. Ageing is also analysed through the political economy perspective, dealing with limited resources and equitable distribution. Humanism, with its 
'sense of place' and 'felt dimension', and social constructionism or constructivism, with its representation of/in spaces, are well covered in the book too. Finally, the authors urge to develop further the relational approach with its focus on in-between spaces and nonrepresentational theory, highlighting the role of practice and performance in geographical gerontology.

The book also discusses specific examples on how initiatives of age-friendly cities, transport policy, and renovating homes all require an in-depth understanding of ageing geographically in order to move away from simplistic neoliberal ideas of independence and autonomy in older age. While governments strongly favour ageing in place, there are strong evidence that resources and services flow towards centres and this also includes the migration of people in older age ( $\mathrm{pp}$ 60-61). Besides, there is a growing diversity of the older population, as well as increased urbanisation, and all these processes, whether people stay put or move, require constant reintegration into places through the ageing process itself.

Ageism should not be naively overlooked in ongoing global trends of ageing and, therefore, the arbitrary, artefactual way of statistically defining people as old, starting with age 60 or 65 , will also need to change in some places and cultures with clearly increasing longevity. One of the most important highlights in this book is the way it pinpoints geographical variations in global ageing. For instance, in 2050 around $80 \%$ of ageing people will live in low-medium income countries in the Global South (p111). Furthermore, ageing is a particular challenge for low- and middle-income countries and it is an urgent question for geographers already now, including the politics of ageing and the variations in the political responsibility for older people between countries. What the book could explore in more detail, though, are the increasingly distinct trends of migration and ageing.

It is fair to say that the book is the most authoritative source in the field of geographical gerontology so far and essential reading for the growing community of geographers across the globe, who are researching ageing in $21^{\text {st }}$ century. 